\title{
Olive Oil
}

National Cancer Institute

\section{Source}

National Cancer Institute. Olive Oil. NCI Thesaurus. Code C1175.

Produced by pressing olives, Olive Oil has a high content of monounsaturated fats, thought beneficial for health. Major components of the phenolic fraction of olive oil, lignans and pinoresinols are potent antioxidants present in extra virg in (first pressed) oils. Containing vitamins $\mathrm{E}$ and $\mathrm{F}$, other antioxidant compounds, foods containing high amounts of lignan precursors may be protective against breast, colon, and prostate cancer, as well as heart diseases. Used mainly in cooking today, olive oil has been used for medicines and in cosmetics. ( $\mathrm{NClO4})$ 